\title{
De festas, viagens e xamãs: reflexões primeiras sobre os encontros entre Waiãpi setentrionais meridionais na fronteira Amapá-Guiana Francesa ${ }^{1}$
}

\author{
Renato Sztutman \\ Mestrando em Antropologia Social - USP, bolsista CEBRAP, \\ pesquisador do Núcleo de História Indígena e do Indigenismo (NHII) e do \\ Grupo de Antropologia Visual (GRAVI)
}

Resumo: Centrado na consideração de algumas experiências de encontro entre Waiãpi do Amapari, Brasil, e Waiãpi do Oiapoque, Guiana Francesa, este artigo propõe uma reflexão sobre as relações intercomunitárias na região das Guianas, norte-amazônico. Focaliza sobretudo as instâncias rituais, reconhecidas como lugar por excelência de troca e confronto de pontos de vista e discursos sobre o habitar um cenário heterogêno que poderia ser designado como "interétnico".

Unitermos: Comunicação intercomunitária, situação interétnica, ritual.

I do not know much about gods; but I think the river is a strong brown god - sullen, untammed and intractable,

patient to some degree, at first recognized as frontier; useful, untrustworthy, as a conveyor of commerce; then only a problem confronting the builder of the bridges.

(T.S. Elliot)

No nordeste da América do Sul, é possível vislumbrar uma região fronteiriça caracterizada não apenas por um limite oficial separando o estado do Amapá, Brasil, e a Guiana Francesa, departamento além-mar do Estado francês. É preciso adentrar a floresta amazônica para visualizar fronteiras que não separam simplesmente, mas fomentam o intercâmbio entre populações diversas - indígenas e não-indígenas. Os Waiãpi, falantes de uma língua Tupi-Guarani, dispersos por ambos os territórios nacionais, se encontram apartados pelo divisor dos países. Essa população, que experimentou diferentes frentes de contato, conforma atualmente dois subgrupos ${ }^{2}$ - o do Amapari, ao 
sul (Amapá), e do Oiapoque, ao norte (Guiana Francesa) - que têm desenvolvido modos de vida distintos, particularmente no que diz respeito ao manejo de sua identidade indígena e ao acesso aos bens ocidentais. Nesse cenário, a fronteira nacional aparece menos como limite que como possibilidade de estabelecer comunicação entre os dois segmentos que, apesar de distanciados no espaço e no tempo, não cessam de se movimentar entre os rios e a floresta da região, abrindo novos percursos e atualizando relações.

A fronteira, representada pelo rio Oiapoque, muito pouco lembrada por brasileiros e franceses e também o único ponto de intersecção territorial entre esses dois países, será pois a paisagem recorrente neste artigo. Povoada pelos trajetos de dois subgrupos Waiãpi, cuja relação tem se mostrado bastante intensa nos últimos tempos, ela se manifesta como zona de contatos, espaço aberto à criação e ao imaginário, mas também ao risco e ao perigo. Buscarei aqui levar a cabo uma reflexão - valendo-me de dados e "reminiscências" da pesquisa de campo, além de etnografias e relatos de outros pesquisadores da região - sobre o encontro entre as duas frações Waiãpi menos centrada nas noções de localismo e permanência que nas de deslocamento e transformação. Para levar adiante meu exercício de análise, sigo com a descrição da viagem que partiu do Amapari rumo ao Oiapoque - ressaltando meus vínculos mais estreitos com o primeiro subgrupo que me conduziu nesse trajeto e com quem compartilhei, mais intensamente, impressões - e da festa que serviu como síntese da experiência de encontro entre os subgrupos Waiãpi.

Ainda que por um curto período de tempo, minha experiência de campo contou com uma situação privilegiada: eu havia sido convidado para acompanhar um grupo heterogêneo - composto por jovens e velhos - de índios Waiãpi do Amapari em sua expedição à terra dos Waiãpi do rio Oiapoque. Entre abril e maio de 1996, acompanhei-os ao longo de todo o percurso: de Macapá, passando pelas cidades do baixo rio, Saint Georges (Guiana Francesa) e Oiapoque (Amapá), até as aldeias do alto em Trois Sauts. Visitamos ao todo cinco assentamentos dispostos à margem ocidental do Oiapoque, dentre os quais, Camopi, o primeiro, ainda no curso médio, era constituído por uma comunidade bastante populosa e que recebe, do governo francês, o estatuto de município indígena. Tal peregrinação contou com uma série ininterrupta de encontros dos habitantes do Amapari com parentes e afins há muito tempo não vistos e com quem se procurava travar novos contatos. Era possível visualizar, neste trajeto, o desenho de um círculo de relações intercomunitárias, que principiava com o estranhamento mútuo e culminava nas animadas festas de caxiri, bebida fermentada de mandioca muito apreciada pelos povos da região. Nas suas primeiras tentativas de estabelecer comunicação com os habitantes do Oiapoque, os índios do Amapari experimentavam momentos de profundo desconforto, não conseguindo distinguir o que lhes parecia familiar - o fato de falarem a mesma língua, de identificarem laços de parentesco (tanto entre os antigos como entre os contemporâneos) e de serem designados igualmente como "os Waiãpi" pelos brancos (brasileiros e franceses) - do exótico que se lhes apresentava - o fato de encontrarem aldeias com ruas pavimentadas, cantinas e ante- 
nas parabólicas, de não reconhecerem as regras básicas de etiqueta e de não serem recebidos da maneira tão cordial, com a qual recebem os seus visitantes. Enfim, fui obrigado conviver, durante toda a viagem, com a dúvida de que se é possível haver identificação entre essas duas frações Waiãpi.

\title{
OIAPOQUE E AMAPARI: CONFLUÊNCIA DE MARGENS
}

Referindo-se aos encontros entre os Waiãpi do Amapari e os Zo'e do Cuminapanema (Norte do Pará), grupos que compartilham muitas semelhanças culturais e lingüísticas, Gallois e Carelli (1996) visualizam os processos de interação intertribal como

\begin{abstract}
“[atendendo] menos a uma política interna de 'resgate' cultural que às necessidades de abertura impostas pela política externa de cada grupo. A relação que cada povo mantém, ou pretende manter, com outros índios foi construída em função das relações que mantêm com os brancos. Por isso, os encontros são ilustrativos do movimento de construção de identidades 'disseminadas' e 'multilocalizadas' mencionadas por [George] Marcus" (1995:213).
\end{abstract}

Para os autores, o diálogo que se estabelece é percebido pelas duas partes como oportunidade para construir, mutuamente, uma nova versão de suas relações históricas com os outros, brancos e índios. O encontro torna explícito interesses mútuos, cada um tendo na apropriação de elementos da cultura do outro a possibilidade de se reposicionar no sistema mais amplo - constituído tanto pelas relações empíricas que travam no cotidiano quanto pelo imaginário alimentado pelo que ouvem falar dos povos distantes e do "mundo dos brancos". É neste sentido que os Waiãpi, reclamando a semelhança entre os atuais Zo'e e seus antigos (tamo-ko), tentam enquadrar os primeiros em suas redes de relações. Esse encaixe é surpreendentemente recíproco, ambos passando a se referir por termos que exprimem relações de aliança - anã (Waiãpi) e ruwanã (Zo'e) -, o que representa uma solução para a relação tensa entre convidados e anfitriões e os inclui em uma categoria mais abrangente - "gente do mesmo povo". Para Gallois e Carelli, trata-se de uma aliança orientada pela situação interétnica, operando por meio de "uma manipulação da história para justificar os interesses do presente e construir uma efetiva aliança entre grupos indígenas que têm uma mesma história de confronto com os brancos (...), uma manipulação do tempo e do espaço do contato, criando novas continuidades" (idem:236, grifos meus).

De maneira análoga, seria possível afirmar que Oiapoque e Amapari não constituem unidades a priori, antes segmentos apartados em sociedades nacionais diversas e, que, portanto, constróem um significado também diverso para sua autodeterminação étnica. Ser, ou melhor, estar Waiãpi recebe apropriações singulares no Brasil 
ou na França, dadas as posturas divergentes desses países em relação às sociedades indígenas e à política indigenista. Semelhantemente ao caso Zo'e-Waiãpi, é possível afirmar que os encontros entre Amapari e Oiapoque são reordenadores à medida que evidenciam interesses opostos, articulam alianças e revelam um embate entre contextos absolutamente desiguais de integração às sociedades nacionais a que se vêem subordinados.

Ao contrário da situação brasileira, caracterizada pela tutela da Funai e pelo estatuto diferenciado da categoria "índio" na Constituição nacional, a política da Guiana Francesa face à sociodiversidade investe em um ideal assimilacionista, tendo como meta fazer dos índios cidadãos franceses passíveis dos mesmos direitos e obrigações que a população da metrópole. Se a Funai representa, no Brasil, um órgão de tratamento diferenciado de sociedades consideradas como incapazes de gerir o seu próprio futuro - operando via métodos paternalistas -, o governo francês, que não conhece órgãos destinados a este tipo de trabalho, tem como horizonte a emancipação - atribuição de cidadania francesa ao índio -, operando pela política de "francização": imposição de currículos nacionais de ensino, assistência médica não-diferenciada, projeto de urbanização das chamadas comunidades indígenas. Enfim, a relação do governo francês para com seus habitantes ameríndios é pautada na crença em um projeto civilizador, ou seja, no investimento em mecanismos de adaptação a um esquema ocidental (francês, particularmente) de modos e valores ${ }^{3}$.

É então possível apontar um abismo entre as relações que cada subgrupo vem travando com os diferentes setores das sociedades nacionais nas quais se vêem inseridos - setores não apenas restritos aos órgãos oficiais de assistência, mas também atrelados a OnGs, pesquisadores e institutos de pesquisa. Mais que a consciência de estarem submetidos a contextos desiguais, os índios de ambos os lados passam a avaliar, a partir das notícias que correm (nos últimos tempos mais intensamente) por entre a região, vantagens e desvantagens de pertencer a uma ou outra província. Pude perceber, no momento de minha estadia no Oiapoque, que as diferentes trajetórias provocavam interesse e curiosidade mútuos; por mais que cada parte afirmasse a preeminência de suas escolhas, depreciando as dos outros, era perceptível um movimento de aproximação. Os índios do Oiapoque mostravam-se muito interessados na políticas locais de autodeterminação - que incluíam práticas de mineração e o processo de demarcação de terras - que os meridionais vinham desenvolvendo em parceria com o Centro de Trabalho Indigenista (CTI), uma OnG que os acompanha há quase 20 anos, e, sobretudo, na postura que eles mantinham como guardiões da cultura Waiãpi face à sociedade brasileira. Os índios do Amapari, à sua parte, mostravam-se insatisfeitos com a imagem de "índios pobres" que os outros faziam deles, revelando-se tão hábeis para trabalhos "de branco" como o garimpo, como para trabalhos "de índio" como a preparação de rituais e de artefatos, coisa que os do norte pareciam estar, cada vez mais, esquecendo. Ao mesmo tempo, vinham de longe para procurar os reputados xamãs, ainda os mais respeitados entre os Waiãpi, que incorporavam, de modo acentuado, elementos mundanos do universo não-índio (bebidas alcóolicas importadas, 
remédios de branco etc.) às suas práticas terapêuticas. A viagem era também uma maneira de fazer consultas xamânicas, obter curas, enfim, aprender com os pajés de lá.

Durante a pesquisa de campo, muitas vezes atado (o que seria inevitável dada minha posição semelhante de visitante) às lentes da fração brasileira ${ }^{4}$, presenciei o mesmo descompasso entre setentrionais e meridionais, desta vez numa atmosfera menos de espanto pela diferença que de aproximações graduais e restritas sob um clima de desconfiança e ambivalência - o que, na verdade, já havia se tornado um ponto de vista estrutural na relação entre as duas frações. Antes de chegarmos ao Oiapoque, Japarupi, Kaintona e Moropi, os jovens do Amapari que, como eu, realizavam a viagem pela primeira vez, alertavam-me que os de lá estavam perdendo sua cultura, mas não negavam o fato de eles serem ótimos produtores (e consumidores) de caxiri, o que prometia mais e melhores festas, em que eles, os jovens do Amapari, poderiam exibir suas habilidades rituais e, assim, conquistar belas moças e receber presentes. Havia, no entanto, um receio de que os do Oiapoque se revelassem maus anfitriões, uma vez que eles se gabavam de sua posição de índios "ricos" e "civilizados".

Torna-se perceptível aí uma assimetria de pontos de vista. Dominique Gallois, pesquisadora dos Waiãpi do Amapá desde 1977, conta que, até a visita de julho de 1991, os habitantes do Oiapoque viam os do Amapari como tamo-ko - os antigos, "avós"-enquanto eles eram os "avançados", "civilizados". Por sua vez, os do Amapari falavam dos outros como "índios aculturados", uma categoria de estranhamento maneira de lhes renegar o estatuto de humanidade plena. Na mútua comparação Nós/ Eles, criavam-se assimetrias de mão-dupla que se revestiam de conceitos advindos de suas respectivas experiências de contato. O norte, exaltando sua proximidade em relação ao "mundo dos brancos" e seus objetos, tomava a categoria civilização, que tomavam de empréstimo da nação francesa ${ }^{5}$, como valor a ser contraposto ao mundo "bárbaro" representado pelo sul. Aliás, a figura escolhida para representar os setentrionais em vantagem dos meridionais, habitantes da floresta, era o rio, o Oiapoque, espaço aberto, próprio à navegação, o que possibilita o acesso - seguro e fácil - às cidades e às mercadorias tão cobiçadas. A instalação fixa - conformando comunidades de tamanho considerável - nas margens desse rio propiciava para o Oiapoque uma autoimagem de índios civilizados, e com isso, uma certa consciência de superioridade de sua própria posição.

Não que os meridionais experimentem uma ausência de trânsito por entre seu mundo e aquele "mais civilizado"; no entanto, quando colocados em relação ao Oiapoque, recobram uma auto-imagem de índios da floresta, o que pode ser traduzido também como índios portadores das tradições dos antigos. Eles acabam por se apropriar de outra categoria ocidental, no caso, a cultura - algo próximo do conceito essencialista alemão de cultura (ELIAS, 1996), algo que remete a uma idealização platônica, que permanece idêntico a si mesmo como substância e resiste a qualquer forma de mudança (CARNEIRO DA CUNHA, 1996). Assim, atentos às demandas e ao imaginário que as sociedades envolventes alimentam em relação a eles, podem se reposicionar na trama tecida em cumplicidade com os do norte, problematizando uma 
assimetria historicamente construída e um certo estigma de inferioridade.

\section{O RIO E A FLORESTA}

Longe de querer estabelecer aqui um inventário das diferenças entre Waiãpi do Oiapoque e Waiãpi do Amapari, gostaria de oferecer, em linhas gerais, considerações a respeito do que se entende pela distinção entre esses dois subgrupos, distanciados por diversos fatores e que se nos apresentam hoje quase como grupos diferentes, a não ser quando insistem em redes de relações sociais comuns ${ }^{6}$ e na continuidade de laços comerciais e matrimoniais. É necessário esclarecer que o encontro entre índios do Amapari e do Oiapoque, que presenciei em 1996, foi povoado por sentimentos ambíguos, que ora apontavam um impulso de reciprocidade (disposição para a troca e para a retribuição), ora revelavam antagonismos entre os grupos. Nesse sentido, o norte era visto, pelos habitantes do Amapari, como lugar da incerteza, onde os parceiros podiam ser ao mesmo tempo inimigos, o que indica o perigo na relação com esses e a necessidade de uma atitude de reserva. Gallois acredita que as visitas ao Camopi deixavam claro que "a memória dos Waiãpi do Amapari sobre suas antigas relações com segmentos do grupo Waiãpi setentrional enfatizava mais os confrontos que as relações amistosas, sendo necessário distinguí-las para entender as expectativas de cada grupo no reencontro" (1988:5).

Na década de 80, por exemplo, quando os Waiãpi do Amapari eram recémcontatados pela Funai, os do Oiapoque eram referidos como amõ-ko, uma categoria de alteridade que inclui a classe de possíveis agressores. Eles representavam naquela época a "outra gente", criada posteriormente pelo herói cultural e então deles separada. Importante notar que com a pacificação no início dos anos 80 das guerras entre o Amapari e os Wayana e Aparai (responsabilizados por grande parte dos infortúnios ocorridos), as acusações recaíam sobre outros possíveis agressores, situados em posições menos distantes no mapa de classificação dos inimigos - Oiapoko Wanoko, o Oiapoque (Gallois, idem). É importante lembrar que os Waiãpi, como a grande parte dos povos guianeses, não deixam de ver na figura de seus'afins reais, aqueles com quem se pode travar relações matrimoniais, um perigo eminente apenas atenuado à medida que o outro, o distante, passa por um processo de domesticação, ou seja, quando é inserido em esferas próximas de troca. Estamos em plena paisagem guianesa que revela filosofias de alteridade para as quais a comunicação com a alteridade ao mesmo tempo que desejada é fundamentalmente temida. O estrangeiro deve ser tornado afim $\mathrm{e} o$ afim consangüinizado, como bem aponta um artigo de Joanna Overing (1983) - toda forma de comunicação com o exterior deve passar, pois, por uma tradução em termos de proximidade, pois o forasteiro é idealmente uma figura malvista. É necessário familiarizar o afim para que ele possa participar das redes de sociabilidade, para que ele possa fazer parte do Nós, tomado idealmente como um todo endogâmico. Contudo, ele ja- 
mais deixará de representar uma ameaça, afinal o afim é também um inimigo potencial.

Interessante notar que a categoria "todos nós", Waiãpi-ko, adquire seu significado apenas no contexto das relações interétnicas, especialmente enfatizado nas reinterpretações da história de contato. Inimigos no início da década de 80 ou parceiros comerciais e matrimoniais a partir de 1990, os habitantes do Oiapoko Wanoko sempre serão, para os do Amapari, possíveis agressores com os quais as relações tendem a um certo grau de perigo. Segundo Gallois, "a essência da sociedade Waiãpi está fora da unidade real" (1988:149) e "a abrangência das categorias do 'mesmo' (...) tem portanto fronteiras fluidas no tempo" (idem:130). No caso da distinção Oiapoque/ Amapari, o que se tem em jogo é uma disposição à fragmentação que liberta os dois grupos de uma homogeneidade histórica e geográfica, para reuni-los, sob o nexo da aliança, cada qual assumindo uma posição particular em um sistema de diferenças que tem em vistas o intercâmbio. Em outras palavras, a dispersão e a descentralização (e mesmo uma não-identidade do grupo como grupo) implicam, antes da autonomia e do isolamento, o estabelecimento de troca e comércio que dá validade à distinção.

Guiados pela idéia de que, após a intensificação do contato com os brancos, "a terra cresceu", os Waiãpi de ambos os lados têm suas categorias de classificação social desdobradas de modo a incluir a diversidade étnica e cultural de seu atual universo. Tendo em vista esse movimento de transformação contínua das categorias de alteridade, eles, situados dentro da paisagem xenofóbica guianesa, deparam-se com a ampliação de suas redes de sociabilidade, apontando uma "gradual neutralização das categorias periféricas de inimigo" (idem:149). Os esforços de restabelecer laços matrimoniais e comerciais - bem como os diálogos (travados a partir de 1986) entre os xamãs de ambos os lados - com os índios do Oiapoque são um típico exemplo de uma opção pacificadora lançada pelo Amapari, que prefere a troca à guerra, na iniciativa de domesticar os afins dentro da categoria do Mesmo, Waiãpi-ko. Os subgrupos Waiãpi permaneceram três décadas sem travar contatos diretos. O encontro que marcou retomada dessa relação - incluindo sobretudo transações comerciais e matrimoniais data de julho de 1991, quando, depois de cinco anos de lentas aproximações, uma comitiva de chefes do Amapari fora formalmente convidada para uma estadia no Camopi ${ }^{7}$. A partir desse momento, as relações entre Amapari e Oiapoque começaram a se intensificar, o que trouxe consequiências importantes e duradouras para a uma nova configuração dos dois subgrupos então reconhecidos como distantes e alheios um ao outro. Antes disso, o Oiapoque permanecia uma província desconhecida e povoada por perigos, dada a fama e a reputação de seus poderosos xamãs. O xamanismo era então um dos principais elos de relacionamento entre os dois grupos, que distribuíam acusações mútuas a respeito de antigas relações, atribuindo o contágio de doenças aos xamãs do outro lado da fronteira. Assim, o processo de aproximação entre setentrionais e meridionais não exclui um sentimento de ambigüidade: aqueles com quem se troca são também inimigos potenciais.

Relatos sobre as diferentes migrações, documentadas desde o século XVII, revelam as disparidades entre a população Waiãpi, constituída de facções variadas. 
Dentre essas disparidades é possível identificar, em um quadro mais contemporâneo, dois movimentos básicos. Por um lado, os grupos do Amapari mostraram-se avessos ao contato, optando pela dispersão na floresta e fechando um círculo de casamentos e de comércio com populações Caribe da região, sobretudo com os Wayana e Aparai; por outro, os grupos setentrionais lançaram-se em uma ocupação nas margens do Oiapoque e em uma experiência intensiva de contato com os brancos, iniciada em meados do século XIX. Desta configuração, uma primeira distinção operante pode ser notada: os índios do rio, que apresentam uma longa experiência de contato, e os índios da floresta, cujo contato efetivo com os brancos se resume aos últimos 25 anos. Importante também salientar o fato de que a relação entre Oiapoque e Amapari remonta contextos conflituosos e até mesmo ataques guerreiros.

Durante as décadas de 1950 e 1960, as relações comerciais entre os dois pólos foi mediada pelo grupo do rio Cuc (que migrou posteriormente ao Oiapoque). Com o advento da Funai e da intensificação da onda de garimpo, o Cuc deixou de ser o grande pólo de obtenção de manufaturas. A forma tradicional das trocas intercomunitárias e intertribais supunha longos circuitos e um comércio a longa distância, o que implicava buscar longe objetos de interesse que, hoje em dia, são sobretudo artigos manufaturados importados pelos brancos, como rifles, espingardas e tecido para fabricar tangas. As relações supralocais preenchiam o cenário, dando espaço para relações de intermédio comercial, que, no caso dos Waiãpi e dos Wayana e Aparai, são reconhecidas pelo termo banaré. Outros grupos, até mesmo os não-indígenas, integram estas intensas redes de comércio no eixo das Guianas, como os negros da Guiana Francesa e do Suriname (os mekoro, segundo a denominação Waiãpi). O advento de novas mercadorias, importadas pelos brancos, punha em movimento novas configurações comerciais, sendo que os mais contatados acabam por assumir a papel dos intermediários entre os brancos e os índios.

A comunidade indígena do $\mathrm{Camopi}^{8}$ foi se tornando um centro de atração pelas possibilidades que oferecia às trocas com os brancos. Não por acaso, as relações entre setentrionais e meridionais se intensificaram nos anos 50 com o advento da política assistencialista (posto de assistência e enfermaria) francesa que tentava recuperar o abalo demográfico causado por uma forte epicemia nos anos 40 . Na década de 50, o Oiapoque representava um ponto de atração pelos privilégios dados aos índios que lá se instalavam. Isso permitiu que em 1954, por exemplo, grupos do rio Cuc se deslocassem para o Oiapoque. A nacionalização do município do Camopi, nos anos 60 , intensificou a política de benefícios - garantia de cidadania francesa aos índios, educação na língua francesa, pensão-desemprego, política de assalariamento etc. permitindo a sedentarização dos índios ao redor do próprio município e nas aldeias do Alto Oiapoque (Trois Sauts), onde foi criada uma espécie de subprefeitura. É neste quadro que Gallois situa o intercâmbio entre os Waiãpi do Amapari e os do Oiapoque: uma relação comercial $^{9}$, na qual a hegemonia pertence aos últimos. E, além do mais, esta relação acaba replicando a dominação que outrora era exercida pelos Wayana e Aparai. Assim, "é mais ilustrativo mostrar que, do nível das trocas, o processo de ex- 
ploração exercido pelos Wayana sobre os Waiãpi do Oiapoque e do Cuc repetiu-se, de modo idêntico, nas relações entre Waiãpi e Waiãpi-puku [do Amapari]" (Gallois, 1986:213).

Tal contexto de dominação comercial equipara superioridade à posse de mercadorias importadas e às relações "positivas" com os brancos (fácil acesso ao comércio). O mesmo se dá em relação aos Waiãpi do Oiapoque, cujo comércio com os brancos foi facilitado de antemão. No entanto, o grau de assimetria entre setentrionais e meridionais não pode ser esgotado nesse comércio desigual: há outras formas de desigualdade em questão que me parecem igualmente relevantes.

\section{CARTOGRAFIAS XAMÂNICAS}

Em 1990, famílias do Camopi, trazendo rapazes solteiros, deslocaram-se para o Amapari e se fixaram na aldeia Mariry. Durante sua estadia, persuadiam os parentes para acompanhá-los na viagem de volta ao norte, alegando que lá eles poderiam fazer muito dinheiro e, principalmente, estariam livres da intervenção da Funai. Nutrido pela imagem da fartura desfrutada pelos da Guiana Francesa, o capitão chegava a cogitar um êxodo, junto ao seu povo, às terras do Oiapoque. $\mathrm{O}$ gendarme francês, uma espécie de chefe de posto militar e guarda da fronteira nacional, concedeu um primeiro parecer favorável, que lhes conferia um pedaço de terra na ilha de Maripa, no meio do Médio Oiapoque, em território neutro, não pertencendo ao Brasil nem à França. No entanto, a possibilidade de uma nova migração foi sendo deixada de lado, à medida que se aproximava o horizonte da demarcação das terras no Amapari e incrementavamse as estratégias locais de organização política à luz da extensão das redes de parcerias com segmentos da sociedade nacional, entre esses, pesquisadores e o CTI ${ }^{10}$.

Em maio de 1991, o capitão Waiwai da aldeia Mariry, que já havia realizado expedições ao Cuc, partia ao Camopi para reencontrar os parentes de sua esposa. Chegando lá, queixou-se de não ter sido recebido devidamente como um "chefe", sentindo-se desrespeitado dada a ausência de hierarquias e etiquetas bem como o desinteresse pelas atividades tradicionais. Impressionava-se sobretudo com a miscigenação interétnica, o que para ele contribuía para o afastamento em relação à cultura nativa. Enfim, sua visita fora marcada por frustrações tamanhas que só seriam compensadas com os encontros com Sisiwa e Wapirã, xamãs poderosos e de muita reputação na região (e inclusive no Amapari).

Em diferente ocasião, o capitão de Aramirã, Kumai, movido pela mesma curiosidade que Waiwai, vai ao Camopi para verificar a eficácia dos pajés de lá e, principalmente, para apaziguá-los em seus ataques maléficos ao Amapari. Gallois, no seu relato sobre a visita ao Camopi em 1991, narra o célebre encontro de Kumai com Sãsõ, o mais velho de todos os Waiãpi, nascido no Baixo Jari (grupo local rival) em uma "linhagem de reputação". Como é de se constatar naquela região, o esquecimen- 
to das tradições tinha como contraponto o desenvolvimento das técnicas xamânicas, o que muito intrigava os chefes do Sul, então movidos pelo desejo de estreitar laços com os parentes distantes.

O retorno de Waiwai, em julho, acompanhado por outras lideranças Waiãpi importantes (como Kumai) da aldeia de Aramirã, tinha como objetivo oficial, além da busca de apoio material, a afirmação do "prestígio do grupo do Amapari e, decorrentemente, somar-se aos 'parentes' para fazer aumentar a 'força' (iane poijy) da etnia como um todo" (GALLOIS, 1991:8). Vislumbra-se aqui um esforço de congregação que visa "juntar forças" para lutar contra os inimigos invisíveis (identificados freqüentemente aos Aparai, aos mekoro e aos brancos). A constituição de uma "unidade" Waiãpi aparece aqui como novidade diante do caminho de diferenciação que ambos subgrupos haviam tomado.

O trânsito entre as duas províncias sob a justificativa de rever parentes e afins, buscar novas formas terapêuticas e adquirir mercadorias ocidentais pode ser compreendido como mecanismo que revela mais do que a ampliação das parentelas, novas possibilidades de cura e satisfação de necessidades imediatas de consumo. Trata-se da apropriação mútua, por ambos os subgrupos, de elementos alheios ao seu contexto local, pois, como afirma Gallois: "se por um lado a contaminação com a alteridade representa perigo, ela também é fonte de poder - o contato controlado com essas categorias garante a manutenção da vida social" (1988:149, grifos meus). A necessidade de se apropriar de itens e conhecimentos pertencentes ao outro para obter "força" é um tema recorrente entre os Waiãpi. Segundo sua mitologia, brancos e índios viviam juntos no início dos tempos, quando a humanidade era indiferenciada ${ }^{11}$. Dada a diferenciação, cada qual efetuou suas escolhas: os tami-wer (antigos dos Waiãpi) ficaram com os arcos e as flechas e os carai-ko com as máquinas e ferramentas de trabalho. Ianejar, furioso com a má-escolha dos Waiãpi, abandonou-os, entregando-os a um mundo violento em que eles deixavam de ser imortais. Doravante, índios e brancos não mais partilhavam a morada celeste do herói cultural. O tema clássico da separação homens e divindades é pois associado à perda do acesso às ferramentas dos bran$\cos ^{12}$.

É na figura dos xamãs do Oiapoque que parece estar contida com mais êxito a tal faculdade de gestão dos poderes advindos da exterioridade - e, mais especificamente, daqueles provenientes do "mundo dos brancos". A concepção de que estes detêm mais poderes, dada sua propriedade invejável de predação e cura, é um ponto fündamental para pensar sua interdependência em relação aos habitantes do Amapari. O deslocamento da fonte dos poderes xamânicos para o norte, sítio de maior acesso aos bens e conhecimentos dos brancos, confere a esta região uma posição privilegiada em detrimento do sul, que tem de recorrer, na maioria das vezes, ao seu intermédio. Mais uma vez a geografia parece servir de metáfora para esses deslocamentos: os próprios Waiãpi do Amapari passaram a reconhecer, dada a retomada dos contatos interregionais, o rio Oiapoque, que traz espanto pela sua largura, como o lugar da criação, o "centro" propriamente dito. Como assume Gallois, 


\begin{abstract}
"Vários de seus trechos são conhecidos por representarem lugares importantes da criação: as grandes pedras redondas são as panelas nas quais os pássaros, recém-criados se banharam, nos dejetos da cobra grande, adquirindo suas cores diferenciadas; embora existam várias nas margens do rio, comenta-se na região que garimpeiros derrubaram a árvore kumaka na qual os pássaros pousaram, fazendo com que seus galhos abaixassem; há ainda um trecho reto do rio que foi delineado pelo vôo inicial dos pássaros, a quem se atribui a formação de todos os rios; os saltos e as cachoeiras, enfim, foram feitos pelo criador Ianejar quando abandonou os homens, etc. ..." (1991:19).
\end{abstract}

\title{
O ENCONTRO FEITO FESTA
}

No caso da expedição que acompanhei, a disposição para festas multicomunitárias era mais intensa que o desejo de trocar objetos. Em outras palavras, a festa de caxiri - recorrente na vida ritual amazônica - apresentava-se como canal de comunicação privilegiado entre os dois subgrupos. Desde o primeiro dia de viagem, os Waiãpi do Amapari faziam alusões às grandes festas de caxiri do Oiapoque que eles ouviam falar ou de que guardavam recordações. A festa era a grande expectativa para os que partiam em viagem, abrindo um horizonte de possibilidades, que ia do estabelecimento de novos vínculos comerciais até a renovação de laços matrimoniais. Enfim, a festa prometia o restabelecimento de "relações de qualidade" (CALBAZAR, 1997) entre subgrupos conhecidos sobretudo pelas suas relações tensas de rivalidade política, acusações xamanísticas e hierarquias comerciais. A idéia de que a festa de caxiri age no sentido de colocar panos quentes sobre os conflitos originários, suspendendo a hostilidade em nome do desejo de intercâmbio e de congraçamento, atualizou-se de maneira peculiar no encontro, em julho de 1991, de lideranças do Amapari e do Oiapoque. Na festa-reunião, decorrente do reencontro de 1991 relatado por Dominique Gallois (1991), transparecia o desejo de retomar relações pacíficas e trocas de diversas naturezas. Da disposição em restabelecer laços e da consciência dos diferentes rumos históricos tomados por cada subgrupo resultava um intercâmbio de experiências de contato.

Como quer Bruce Albert (1985), as instâncias rituais nos permitem vislumbrar, para além do enfoque usual no grupo local, um campo de operacionalização de uma estrutura de comunicação intercomunitária. De uma maneira geral, tais festejos evocam instâncias supralocais, ou seja, momentos em que o grupo se abre à exterioridade, fazendo com que a afinidade, então o idioma predominante nessas ocasiões, englobe os domínios da consangüinidade (VIVEIROS DE CASTRO, 1993). O que se costuma verificar é a reunião de grupos locais dispersos no espaço, e, quando não se verifica esse estado de dispersão, mas sim contextos de aglomeração, o caráter da reunião é dramatizado engenhosamente. Se a distância não é dada de antemão, ela é ao menos representada, pois é justamente sob este critério que o ritual vai se desen- 
rolar. A festa é, neste sentido, expressão da afinidade e, para existir, deve partir do pressuposto da existência de grupos diferenciados para que possa se dar o corte elementar entre anfitriões - aqueles que oferecem o pátio da aldeia e a bebida - e convidados - aqueles que providenciam a caça, os cantos e danças.

Colocadas essas questões, gostaria de propor uma definição, heurística e provisória, tendo em vista o caráter de oposição entre os grupos no interior dos rituais coletivos. Por festa entendo pois todos aqueles eventos que, guiados por um programa de sociabilidade que se destaca da vida cotidiana, são capazes de conformar uma coletividade, trazendo à tona temas e celebrações referidos à vida em sociedade e à possibilidade de tal ato. Trata-se do esforço de "re-união" (para usar uma expressão de PIERRE BOURDIEU, 1980) de esferas que se percebem (e se afirmam) distantes e contrárias. São eventos sobretudo capazes de postular uma humanidade possível face à diversidade efetiva que sustenta as relações sociais. Subjacente a essas práticas operam princípios de afinidade, fundadores, de um modo geral, do socius ameríndio, que tem como horizonte a idéia de que o de fora é sempre portador de perigo, logo deve ser recebido com cautela e sua agressividade original deve ser domesticada (OVERING, 1983). Tais especulações conceituais reenviam-nos à situação do encontro entre Oiapoque e Amapari mediado pela festa, que se revela por um movimento duplo de demarcação das posições de cada um dos subgrupos como portadores de diferentes capitais (incluindo objetos materiais, ferramentas e também conhecimentos rituais $\mathrm{c}$ xamânicos) e de subversão das fronteiras que os segregam pela projeção de um estado de indiferenciação social e, paralelamente, pela apropriação de uma categoria genérica - e sobretudo importada-de "índios".

Voltemos, então, aos encontros entre Amapari e Oiapoque e às festas que daí resultaram. Em julho de 1991, ano da retomada dos contatos, os índios do Amapari recebem um convite especial da Associação dos Ameríndios da Guiana Francesa (AAGF) e da prefeitura do Camopi para uma "festa-reunião" neste mesmo município. Pela primeira vez, o encontro não era iniciativa de famílias isoladas, mas sim dos órgãos governamentais. A Associação, a gendarmerie e o prefeito se mostravam muito interessados com a retomada das relações além-fronteira, tanto que resolveram formalizar o convite, enviando um pedido de permissão à Funai para que os Waiãpi do Amapá participassem do evento. A carta oficial foi destinada aos chefes costumeiros das aldeias convidadas, enfatizando que o povo do Amapari seria recebido como hóspede especial. Dois eram os interesses dos franceses: que os do Amapari dançassem e que discutissem com os outros suas experiências fundiárias, tendo em vista uma vasta experiência em relação ao garimpo e uma longa história de reivindicação de direitos territoriais, pontos que não eram enfrentados politicamente pelos Waiãpi na Guiana Francesa. Os interesses crescentes do Oiapoque em relação ao Amapari podem ser sintetizados com a seguinte afirmação do Prefeito do Camopi, Paul (um Waiãpi, ao contrário do atual prefeito Joseph, um Emerillon): "queremos lembrar que somos índios, dançando todos juntos..." (apud GALLOIS, 1991:11).

Assim como nos episódios anteriores, a experiência de encontro que acom- 
panhei em 1996 apontava, apesar de alguns esforços por parte dos oficiais franceses e dos índios de ambos os lados, a precariedade do projeto de construção de uma unidade propriamente Waiãpi para além das disparidades entre os subgrupos apartados por uma fronteira multifacetada. Poderia dizer que, até o momento da festa de despedida na aldeia Yawapá do Alto Oiapoque, havia sido criado um clima de insatisfação por parte de meus companheiros do Amapari. Esses, perplexos com a falta de receptividade da população do Camopi, cuja infra-estrutura causava-lhes desconforto, não desistiram de sua empreitada inicial: estabelecer contato com os Waiãpi da Guiana Francesa, seja criando novos laços de sociabilidade, trocando flechas por munição e sobretudo exibindo seu dotes rituais. Depois de quatro dias de más refeições (dada a escassez de caça, ingestão de alimentos enlatados comprados na cantina) e muita bebida alcóolica (caxiri mas também cachaça, cerveja e whisky, essas últimas designadas como tafiá, bebida de branco), partíamos ao Alto Oiapoque, Trois Sauts, em busca de "relações de qualidade" (CALBAZAR, op. cit.) com as gentes de lá.

Gostaria de acrescentar que, desde nossa partida, em Macapá, não parava de ouvir considerações sobre a fama etílica dos moradores do Oiapoque. Comentários, como "o pessoal do Camopi e de Trois Sauts não trabalham, só bebem", "todo mundo lá é bêbado", "o povo de lá não é bom: só bebe", eram freqüentes entre os do sul. Apesar de soar depreciativas, essas falas continham algo que expressava fascínio. Não por menos, ainda no Camopi, quando voltava de uma caminhada noturna para nosso corbet, cruzei com Japarupi que, totalmente ébrio, chegava de uma noitada na Vila Brasil, onde, na margem oposta do rio, bebiam junto os do Amapari e os do Oiapoque, nutridos da exaltação típica das festas de caxiri em que os anfitriões embebedam os seus convidados, tornando-os vulneráveis e suscetíveis ${ }^{13}$. Japarupi, arrependido, dizia-me que eles o tinham forçado e que simplesmente não queria beber. Falava que aquilo era bebida de branco e que, para ele, bom mesmo era só a festa de caxiri que os outros Waiãpi, em Trois Sauts, estavam preparando para ele e seus parentes.

Na manhã seguinte, partíamos ao Alto Oiapoque. Os comentários dos outros sobre a bebedeira na Vila Brasil escondia o júbilo sob um discurso um tanto pejorativo. Mas as relações de hostilidade alimentadas em relação aos residentes do Camopi estavam atenuadas, afinal eles haviam oferecido algum tipo de festa, mesmo que fora da aldeia, com bebida de branco, coisa que se faz muito em Macapá. Finda a festa de tafiá, eles desejavam a festa de caxiri, em que, como bons convidados, iriam dançar e tocar, exibindo para os parentes do lado francês que não perderam o conhecimento dos antigos.

A festa de despedida na aldeia de Yawapá fora resultado de uma ação conjunta dos quatro grupos locais do Alto Oiapoque em homenagem à visita dos parentes distantes do Amapari. Havia naquele dia um sabor especial das grandes comemorações multicomunitárias ${ }^{14}$. A celebração se dava entre grupos bastante distintos. Ora, a distinção aumentava o entusiasmo dos participantes, reunindo interesse das duas partes envolvidas e acirrando a separação entre convidados (os parentes do Amapari) e 
anfitriões (os residentes do Alto Oiapoque e, de certo modo, todos aqueles do Oiapoque, já que muitos do Camopi haviam viajado conosco só por causa da festa) ${ }^{15}$. Por um lado, o Oiapoque preparava a festa para os parentes que raramente lhes faziam visita, aproveitando para esbanjar o ótimo caxiri, produzido em grande escala e qualidade pelas suas mulheres, suas mercadorias importadas da metrópole, seus aparelhos de som e suas bijuterias trabalhadas; como doadores de bebida, permaneciam como espectadores das performances atuadas pelos parentes. Por outro, os do Amapari tinham, finalmente, espaço para exibir seus talentos como caçadores (chegamos a Zidock com um carregamento razoável de caça, incluindo o guariba, carne tão apreciada por eles), dançarinos e músicos.

Assim, em cooperação, todos produziam as flautas de taboca e os chocalhos de buriti que completariam o Turé, cerimônia das flautas. O caxiri, como sempre, abriu a celebração, sendo seguido da comida igualmente preparada pelas mulheres. Em rápidos golpes, cada qual virava sua cuia, e, como era de se esperar, em pouco tempo estavam todos ébrios, prontos para cantarolar as primeiras estrofes e para executar a música dos instrumentos. Na seqüência, levantavam-se os do Amapari, dirigindo-se ao pátio, onde se desenrolava a dança. Os seguiam na dança alguns dos membros do grupo anfitrião, enquanto as mulheres, eficientes e dadivosas, dirigiam-lhes novas cuias. Os anfitriões impressionavam-se com o brilho que aqueles do Amapari conduziam a festa, não deixando de impor as etiquetas tradicionais nos bate papos mais informais e colocando-se politicamente face a problemas fundiários e políticos. Os convidados, por sua vez, impressionavam-se com a profusão de bebidas alcóolicas (o tafiá então vislumbrado pelo seu poder fortificante, quase como um remédio) ingeridas com o caxiri.

"Tire mais fotos", dizia-me Japarupi. Era importante para eles que tudo fosse registrado: que eles haviam dançado bem, que haviam caçado com destreza, que haviam despertado interesse nas mulheres do lado de lá. A festa só acabou, tarde da noite, com o fim da grande canoa de caxiri. Mas, logo em seguida, alguém da aldeia Trois Sauts se pronunciou, anunciando mais e melhores canoas naquele lugar. Já era tarde, e, quando chegamos à quarta aldeia do Alto Oiapoque, as mulheres de lá, então completamente ébrias, nos aguardavam com ansiedade. Em vez dos sons das tabocas e dos cantos masculinos, um aparelho de som entreteria aq̣uela orgia selvagem (que não tinha a menor preocupação em terminar) com melodias quentes importadas da região caribenha. No dia seguinte, dia também de nossa partida, Japarupi, Kaintona e Moropi contaram-me sobre seus êxitos noturnos: que tinham bebido muito, que tinham dançado muito e, o melhor de tudo para eles (o significado mais imediato da festa de caxiri), que tinham conquistado muitos corações.

\section{O ESFORÇO SINTÉTICO DO RITUAL}

O dia da partida reproduziu, inversamente, a sequiência da chegada. Paráva- 
mos em cada aldeia para despedidas, e, para recompensar os do Amapari pela sua bela performance, os anfitriões ofereciam-lhes presentes dos mais variados tipos, na maioria das vezes, mercadorias importadas da metrópole. Assim, o Alto Oiapoque afirmava sua generosidade interessada, retribuindo o máximo possível a presença daqueles estrangeiros, com quem pretendiam estreitar laços rituais, comerciais e matrimoniais. Por sua vez, os Waiãpi brasileiros aceitavam com alegria os presentes concedidos, prometendo um regresso e reafirmando convites para uma futura viagem ao seu país.

De volta ao Camopi, não pude presenciar qualquer manifestação festiva (guardava o entusiasmo das festas dos dias passados), já que meus companheiros, exaustos, desejavam retornar aos seus lares. Além disso, um mal-estar em relação ao prefeito do município - acusado de conchavos com a ala corrupta do governo em Caiena, além de feitiçaria, mortes e crimes inconstitucionais - foi responsável pela ira dos Waiãpi do Amapari e pelo nosso repentino abandono do território francês com destino à cidade do Oiapoque. Ao negar-nos auxílio para obter combustível para o retorno a Saint Georges e, mais uma vez, oferecer-nos uma péssima instalação na aldeia, a hostilidade era refeita em detrimento do congraçamento vislumbrado no dia anterior.

Na certeza de que obtiveram êxito em suas empreitadas rituais pelas terras francófonas da Guiana Oriental, os Waiãpi do Amapari revestiam-se de um discurso missionário. Ao abandonar o município do Camopi, ressentidos com os maus tratos do prefeito Emerillon, eles prometiam um retorno, justificando que era preciso "ensinar os parentes do Oiapoque" as artes rituais Waiãpi. É assim que, diante da paisagem desfigurada das comunidades setentrionais, os meridionais assumem para si o estatuto de "depositários de todas as tradições, uma espécie de antídoto contra a extinção" (GALLOIS, 1991:22). Para tanto, era necessário "limpar" a região e, nesse sentido, o discurso do Amapari é notadamente moralizante: "os jovens de lá têm de dançar para deixar a cachaça, têm de reaprender os costumes tradicionais para não deixarem de scr Waiãpi", afirma Japarupi, indignado.

O sucesso da festa de despedida em Trois Sauts, evidenciado pela retribuição da população local com presentes, estreitamento de laços e convites para visitas futuras, acaba por reverter o quadro de subordinação vivenciado nos primeiros dias de estadia no Oiapoque. Se, antes, os Waiãpi da banda brasileira eram tidos como aqueles que têm pouco para trocar, no final, eles assumiriam uma posição privilegiada de detentores por excelência dos conhecimentos rituais, e, de certa forma, da cultura Waiãpi em sua expressão mais geral. Doravante, sua posição no circuito de intercâmbios é alterada sobretudo devido à definição da cultura como patrimônio a ser trocado. Este redimensionamento das relações Oiapoque-Amapari, numa espécie de "autoconsciência da cultura como expressão das demandas políticas e existenciais" (SAHLINS, 1995), se deve, de forma mais ampla, às transformações da auto-imagem que cada grupo foi constituindo para si em sua experiência interétnica.

A conversa que presenciei entre os Waiãpi meridionais e o gendarme do Camopi foi muito esclarecedora. Foi possível entrever uma situação em que a comuni- 
dade indígena do Oiapoque (incluindo as aldeias do Alto e do Médio curso do rio e seus interlocutores não-índios) afirmava uma dependência em relação ao Amapari no que dizia respeito à construção da imagem de "índios autênticos", "índios de verdade". Com efeito, o gendarme retomava a proposta de trazer para o Oiapoque famílias do Amapari. Valendo-se de um discurso que associava a situação dos índios no Amapá à pobreza e à precariedade de recursos sanitários, educacionais e relativos à segurança, o oficial francês abria a possibilidade para que estes se instalassem junto aos seus da Guiana Francesa. Prometia ainda que em alguns anos após a instalação, iriam adquirir o estatuto de cidadãos franceses, o que lhes garantiria direitos e regalias, além de um status de civilização tão enfatizado pelos parentes do norte. Interessante perceber que o gendarme articulava muitas das trocas com as gentes do Amapari, encomendando arcos e flechas em troca de munição, entre outras coisas. Scu trabalho de salvaguarda e fiscalização da fronteira, impedindo a invasão de garimpeiros e aventureiros em geral vindos do Brasil, assumia também a função de produção de uma imagem do ameríndio da Guiana, frequientemente calcada em ideais de pureza e intimidade (ou ação conservacionista) com a natureza. Este revelava também um desejo de aproximação com os meridionais, uma vez que eles teriam aprendido a preservar sua cultura e seus conhecimentos - especialmente os rituais.

O desfecho de tal conversa foi, entretanto, rápido. Os jovens Japarupi, Moropi e Kaintona se recusaram a aceitar o convite, já que acabavam de encerrar o processo de demarcação de sua área, ou seja, haviam alcançado direitos sobre o território batalhados durante anos; seria, logo, incoerente mover-se após todo esse trabalho em nome da autonomia e da autodeterminação. Apenas o capitão Matapi, representante dos velhos, mostrou-se confuso diante da proposta, deixando-se seduzir pelas promessas do oficial francês e pela possibilidade de desvincular-se da Funai e ascender economicamente. De qualquer forma, a proposta indicava que uma nova situação se configurava: a cultura Waiãpi era tomada como valor dentro de um sistema mais amplo de interesses. Tudo isso apontava um estado de coisas em que a cultura, tomada em seu sentido essencialista usual, deixava de ser percebida como empecilho à civilização, tornando-se algo de que dever-se-ia orgulhar. Em tal contexto, a diferença cultural passava a representar um dado importante para a construção de um ideal nacional menos expansionista, adequado às novas demandas de conservação ambiental e preservação de patrimônios etnológicos (LEPRETE, 1996).

Nas décadas de 80 e 90 , relatos de antropólogos e indigenistas atentavam ao caráter etnocidário da política oficial de francização e à conseqüente deterioração das formas tradicionais de subsistência e sociabilidade entre os índios do Oiapoque. $\mathrm{O}$ Camopi, em particular, era retratado como lugar dessas atrocidades, atestando quase uma rendição por parte da população às perversões da sociedade moderna. Nessa paisagem fáustica, um futuro negro era atribuído aos índios que trocavam suas atividades primordiais - a caça, os Turés, etc. - pelo consumo de mercadorias importadas e, sobretudo, pelo vício alcóolico. Mediante tais considerações, os índios se sentiram ofendidos em sua auto-imagem: era-lhes destituído o estatuto de autenticidade cultural, 
o que os situava num patamar não só de perda cultural, mas também de degradação moral. Diante desse estado de coisas, o Amapari passou a representar uma possibilidade de reversão para o Oiapoque: seria possível, por meio da promoção de novas situações de intercâmbio com esses, (re)construir para si uma imagem de autenticidade. É assim que a experiência dos Waiãpi no Amapá, com sua saga reivindicatória, passa a interessar à comunidade do norte: é preciso saber se colocar diante da sociedade mais ampla, forjando para si uma unidade por improvável que ela possa ser.

É fundamental acrescentar que o projeto de implementação do Parque Nacional da Floresta Tropical Guianesa tem gerado um sério debate sobre o lugar das populações indígenas em um território supostamente predestinado à conservação ambiental. Desta forma, o esforço dos ideólogos desse projeto tem sido o de promover uma associação entre os índios e a salvaguarda da natureza. A proposta exige que os índios sejam definidos como sintonizados com o meio ambiente dada a disposição de sua cultura à conservação ambiental. O mito do "índio naturalista", então projetado na figura dos índios do Amapari (uma vez que os do Oiapoque são reconhecidos como por demais civilizados), é o que orienta a iniciativa do governo francês em atrair a população do sul. Trata-se de uma estratégia de reconstrução da identidade Waiãpi a partir da incorporação dos conhecimentos dos índios do outro lado da fronteira. Desta forma, os interesses da política oficial casam-se com os muitas das famílias que habitam o Camopi e Trois Sauts. Estas, tendo em vista um horizonte de articulação política emergente (associações indígenas em Caiena) e a conquista de direitos diferenciados em relação à permanência e usufruto em seu território, passam a cogitar a reformulação de sua auto-imagem perante a sociedade nacional. Tomadas como expropriadas de sua cultura original, as populações Waiãpi do Oiapoque passam a reivindicar para si um estatuto indígena, aquém de todas as suspeitas e dúvidas. Ora, essa associação passa pela imagem de índios puros em harmonia com o meio ambiente e não por aquela veiculada pelos etnólogos. Torna-se então clara a necessidade de recriação da imagem do índio autêntico, para fins ao mesmo tempo nacionais e identitários.

O espaço da festa, tomada por sua potencialidade multicomunitária e pela possibilidade de manipulação de categorias advindas do contato - cultura e civilização, por exemplo-, torna-se privilegiado nesse processo de ("e)construção ${ }^{16}$. Cabe à festa, partindo de fragmentos locais e regionais, reconstituir, ainda que provisoriamente, uma unidade maior, produto da intensificação das relações com grupos vizinhos. Tendo em vista essa demanda, o conhecimento ritual detido pelos habitantes do Amapari é imediatamente reconhecido como valor. Os índios brasileiros se sobressaem porque sabem montar a festa "como se deve", manejando muito bem o repertório de cantos e danças que os parentes franceses esqueceram. Nesse momento, o savoir faire ritual passa a ser reconhecido como capital tão importante quanto os bens materiais e os saberes xamânicos no interior do mercado interétnico constituído naquela região. É assim que Simon Harrison, traçando um paralelo com a economia do dom analisada por Marcel Mauss, trata das prerrogativas rituais como formas de propriedade intelectual. O simbolismo ritual, sob tal perspectiva, pode ser equiparado a bens de pres- 
tígio, prestígio notadamente intelectual. E, assim, a função comunicativa dos bens pode também ser equiparada à das ações rituais, uma vez que estas "are incarnated signs, actions with rethorical function of signifying political relationships" (HARRISON, 1992:237).

A intriga intercomunitária que se faz notar no circuito Amapari-Oiapoque apresenta-se de maneira multifacetada, revelando assimetrias irredutíveis que conformam situações caracterizadas pelo embate de diferentes pontos de vista - o do rio e $o$ da floresta. Tais assimetrias atualizam-se sobre dois níveis de circulação de mercadorias, materiais e imateriais: fluxo de mercadorias manufaturadas e fluxo de conhecimentos rituais - igualmente tomados como mercadorias. Esse segundo nível aponta para uma nova totalização do espaço das relações que suspende o privilégio do rio, invertendo a hierarquia (norte sobreposto ao sul) que opera no primeiro nível. Desta maneira, as relações hierárquicas que se travam na região culminam por ser relativizadas; pois, como esclarece Louis Dumont: "A hierarquia abre, assim, a possibilidade de retorno: aquilo que era superior em um nível pode se tornar inferior num nível inferior”" (1995:374).

Guiando-me por essa noção de hierarquia proposta por Louis Dumont, quando penso na relação Oiapoque-Amapari, não penso em um caso equistatutário, em termos de partes complementares e excludentes, mas em um caso concêntrico, em que, dependendo do nível, o que era uma unidade superior pode ser tomado como elemento distintivo. Colocada como artifício, a hierarquia - uma relação a qual se pode denominar "englobamento do contrário" (DUMONT, op. cit.) - deve ser compreendida como intrinsecamente bidimensional, pressupondo uma referência em relação a um nível específico. "Diferentemente da simples relação distintiva, a relação hierárquica inclui a dimensão de valor" (idem:373).

No que se refere ao plano do fluxo de mercadorias e de poderes xamânicos (aqui referidos pelo seu poder de aglutinar forças exógenas identificadas ao universo extra-indígena), os Waiãpi do Amapari são relegados à condição de índios pobres, tradicionalistas e atrasados, ocupando a periferia do sistema. Os do Oiapoque, por sua vez, destacam-se como civilizados, avançados, caracterizados por sua posição privilegiada no sistema. São eles que detêm a "força", associada à posse das ferramentas ocidentais (recobradas do tempo fatídico da má-escolha) e à concentração de saberes xamânicos eficazes na cura e também na destruição. Aqui, no plano das relações comerciais e xamânicas, o rio engloba a floresta, a civilização engloba a cultura.

No que se refere ao plano da circulação de conhecimentos rituais, tomados aqui no sentido de propriedade intelectual, a floresta engloba o rio, a cultura engloba a civilização. O ponto de vista abarcado pela floresta, depositária dos conhecimentos rituais, torna-se privilegiado diante do rio, lugar onde "as tradições estão se perdendo". A posição hegemônica passa para as mãos dos membros do Amapari, reafirmando-se como detentores da verdadeira humanidade em detrimento daquela residual própria aos caraiko e parainsi-ko, dos quais se aproximam os do Oiapoque. Nesse ponto, prevalece a idéia de que optar pela cultura não é de todo má, principalmente se ela pode entrar para o rol das mercadorias, firmando-se como patrimônio a ser trocado. 
É no interior do ritual que os agentes se dão conta da produção de novos valores para as relações que continuam a se definir pelo idioma de afinidade. No caso da relação assimétrica entre Oiapoque e Amapari, os valores emergentes, os conhecimentos rituais, são a própria condição de produção da festa. Como apontado anteriormente, o consumo do caxiri por si só - prática freqüente no Oiapoque - não define as instâncias festivas "grandes", preenchidas necessariamente pela música e pela dança. Para restabelecer o circuito de dons, é necessário resgatar o lugar dos dançarinos e cantadores - os visitantes por excelência - no interior ritual. Na carência de propriedade e autoridade para definir o conteúdo de um ritual coletivo entre as comunidades do Oiapoque, busca-se um modelo entre os grupos do além-fronteira, que passam a representar curiosamente o "elo perdido da tradição" (GALLOIS \& CARELLI: 1995).

A intriga complexa que acabo de apresentar, por certo de maneira precipitada, permite vislumbrar um metassistema - Oiapoque-Amapari - posto em constante movimento pelas assimetrias que se produzem no seu interior. Dada a atual sobreposição de diferentes eixos de circulação de dons, sobretudo imateriais, é possível afirmar que não há nesse metassistema ponto de vista privilegiado, uma vez que a posição englobante assumida pelo Oiapoque pode ser subvertida, sendo englobada em outro momento. Estaríamos diante do modelo de dualismo concêntrico apresentado por Claude LéviStrauss: "um sistema que não se basta a si mesmo e que deve sempre ao meio que o circunda" (1976:177).

Vislumbramos para esse metassistema um horizonte de complementaridade, necessário para a construção do Nós desejado, mas improvável de ser alcançado, uma vez que as desigualdades e assimetrias não deixam de operar e se revelam fundantes. Os níveis jamais se justapõem, a barganha entre norte e sul permanece então em aberto. A festa é incapaz de promover a integração dos diferentes pontos de vista, remete apenas a um acordo provisório entre eles. A congregação das "forças" para forjar uma imagem de unidade e autenticidade, como resposta a uma demanda alheia, jamais se completa. Assim, a busca pela conjunção de unidades notadamente discretas por meio do restabelecimento da continuidade entre experiências díspares não encontra êxito. No eixo Amapari-Oiapoque, a construção da unidade como algo estável, fixo e constante permanece por fazer. Mas nem por isso cessam os esforçøs para alcançá-la, muito pelo contrário. Certamente, naquela região os encontros mediados pelas festas e viagens não deixarão de existir.

\section{NOTAS}

1 Este trabalho foi originalmente apresentado no GT de Etnologia Indígena, coordenado por Dominique Tilkin Gallois e Denise Fajardo, no XXI Encontro Anual da Anpocs, Caxambu, outubro de 1998. Agradeço às coordenadoras e a Aparecida Vilaça, debatedora da mesa, pelos comentários tecidos.

2 O termo "subgrupo" não diz respeito a uma categoria nativa, tampouco a um conceito 
antropológico propriamente dito. Não designa uma unidade sociológica precisa, antes um agrupamento regional que se define pela sua determinação histórica. Assim, o que me permite pensar Oiapoque e Amapari como dois subgrupos distintos é o fato destes terem desenvolvido diferenças marcantes a partir de trajetórias muito diversas de contato com as sociedades nacionais envolventes.

3 A luta, familiar ao Amapari, pela autonomia política e pela demarcação de um território reconhecido como próprio aos índios é desconhecida no Oiapoque, que conforma uma política comunitária integrada ao governo francês - dada a operação de cargos políticos ocidentais, tais como o de prefeito e de vereadores - e uma definição estreita do território em termos de "zonas de direito de uso coletivo tradicional e de subsistência" (LEPRETRE, 1996). O território destinado à ocupação indígena tende a ser reduzido à categoria de "zona de vida", espaço de ocupação humana permitido no interior de uma área reservada à conservação ambiental, tal como propõe o Projeto para a criação do Parque Nacional da Floresta Tropical Guianesa. Este, longe de problematizar a posse e o usufruto do território, relega os índios ao papel de meros ocupantes, aqueles que lá estão apenas para conserválo, protegê-lo de predadores externos. É neste sentido, que, com o advento do Parque Nacional, a postura governo francês e seus assessores fazem transparecer um paradoxo que lhes é constitutivo: como conciliar um ideário de salvaguarda da natureza com a imagem dos índios emancipados, civilizados.

4 Aliás, atado sobretudo às lentes dos mais jovens, já que é reconstituído um embate de pontos de vista entre eles e os velhos. Trata-se de um embate entre tradição e inovação Waiãpi. O discurso dos velhos que presenciei consistia justamente na repreensão dos jovens quanto ao seu comportamento desregrado e maior volubilidade em relação ao modo de vida setentrional. Interessante notar que, juntos, jovens e velhos faziam as mesma ressalvas quanto ao modo de vida setentrional, identificando ali um estágio de perda e esquecimento das tradições.

5 Norbert Elias (1996) é quem aponta à "sociogênese" do conceito de civilisation na França, identificando aí o projeto de ampliação da sociedade aristocrática e a incorporação da burguesia, o que implicava a propagação de certas maneiras pretensamente universais em contraposição a um modo de ser bárbaro. Interessante notar como csta catcgoria - a civilização - problematizada por Elias é ainda hoje operante nos encontros da sociedade Ocidental com populações tradicionais e na fundação de ideologias assimilacionistas. $\mathrm{O}$ caso da Guiana Francesa é, neste sentido, exemplar, basta tomar o cerne da política de francização: levar a politesse, a civilité para a bárbarie original às sociedades indígenas. Mais interessante ainda é como essa categoria, ocidental e francesa por excelência, é tomada pelos índios da Guiana como distintivo em relação aos do Amapá; ela perde seu referente inicial e empresta-se a um comércio simbólico de natureza diversa.

6 A discussão sistemática sobre redes de relações sociais e parentesco Waiãpi encontra-se em Dias Calbazar, 1997.

7 O que foi marcante para a retomada do encontro de 1991 - aliás, uma intervenção proposital de Dominique Gallois, incitada pelos relatos da população do Amapari sobre as gentes de lá e o sistema de acusações xamânicas mútuas - foram as reminiscências de encontros antigos que eram realizados no contexto de longas caminhadas (duas a três semanas) subindo o rio Inipuku, passando pelo Cuc e chegando ao Oiapoque pelas cabeceiras. Ir 
pelas cidades, Macapá e Oiapoque, foi algo completamente novo, onde a geografia nacional constituía uma nova realidade para os Waiãpi. Quando viajavam pelo trajeto dos antigos, circulavam em terra Waiãpi, sem se dar conta da fronteira nacional (GALLOIS, comunicação pessoal).

8 Ao contrário do que se observa entre os Wayana e Aparai, a convivência entre Waiãpi e Emerillon, ambos grupos Tupi, no município indígena do Camopi não resulta de uma integração, mas sugere uma subordinação dos últimos em relação aos primeiros, ainda que os Emerillon sejam temidos devido ao seu suposto poder de pajelança. Contudo, podese afirmar que entre estes dois grupos, cada qual mantém sua autonomia.

9 Gallois (op. cit.) faz referência à importância, para este sistema de alianças comerciais, da instituição peito que possibilita a agregação de "outros". Em termos gerais, peito (termo caribe) diz respeito à relação sogro-genro e ao mesmo tempo ao termo poiti, que quer dizer escravo de guerra. Anda próximo da categoria tairo, equivalente a cunhado, ou seja, aquele que é incorporado via aliança. Em outro nível, peito pode designar aquele indivíduo que deixou seu lugar de origem, podendo até ser de outra etnia. De qualquer modo, a termo peito descreve relações que não pertencem à esfera do parentesco, mas sim ao âmbito econômico (a propósito dessa discussão sobre relações de parceria comercial nas Guianas, FARAGE, 1991).

10 Ainda em 1990, rapazes do Camopi casavam-se no sul, dando início a um movimento de ampliação das redes de aliança. Os Waiãpi da margem brasileira deixavam transparecer uma certa política de trazer mulheres do Camopi para casar no Amapari, tendo como objetivo aumentar o controle dos sogros sobre seu grupo local (retenção de mais mulheres). Importante notar que o tema matrimonial permanece, hoje em dia, como um tema crítico no Amapari, uma vez que tal investida raramente se concretiza. É comum ouvir dos capitães reclamações a propósito desse infortúnio, dada a nostalgia dos tempos em que eram freqüentes as trocas matrimonias com a população do rio Cuc (GALLOIS, informação pessoal).

11 Tendo em vista esses exemplos, é possível pensar os brancos como integrados estruturalmente em um esquema preexistente. É assim que Gallois compreende a figura dos brancos como "totalmente incluída no sistema, assumindo uma posição de mediação no movimento cósmico onde se inscreve o devir da humanidade. Pelo potencial tecnológico, pela violência e pela contaminação, os brancos têm influência sobre o movimento, apressando, por via de seu comportamento inadequado, o cataclismo que, mais uma vez, destruirá a humanidade" (1988:348).

12 De maneira semelhante, Carlos Fausto (1997) nos apresenta à cosmologia Parakanã, grupo Tupi-Guarani do Pará meridional, que associa os brancos (toria) aos grandes xamãs e demiurgos, capazes de ressuscitar os mortos por meio da utilização de remédios. Os brancos são sobretudo vistos pelos Parakanã como "senhores dos objetos", cuja conotação é ambígua na maioria das vezes: ora são reconhecidos pelos índios como fornecedores e parceiros, ora como inimigos. $\mathrm{O}$ autor não interpreta o impacto de bens materiais em termos de "revolução tecnológica", mas como escolhas sócio-políticas diversificadas, identificando nos objetos "signos dos poderes da exterioridade que cumpria capturar, incorporar e fazer circular" (1997:316) e índices de poder xamânico elevado. O desinteresse pelas ferramentas no sentido de aparatos tecnológicos deixa transparecer uma necessidade de 
outra ordem. "O espaço político e as relações interlocais erguem-se menos sobre a troca comercial do que sobre o fluxo de corpos e bens imateriais, operado pelo casamento e pela guerra" (idem:324).

13 Na Amazônia, a dádiva de bebidas, ato de generosidade por assim dizer, parece surgir curiosamente submetida a um idioma de agressão. Embriagar nesses termos é sobretudo tornar o outro vulnerável, ou, para usar uma linguagem canibal, torná-lo presa, fazer dele um objeto da predação. Canoas e cuias constituem, dessa forma, armas poderosas que tomam lugar no "cocktail sauvage" (Albert, 1985) constituído de pessoas de diferentes grupos: o convite à bebida aproxima-se aqui de uma tática de guerra.

14 O conjunto multicomunitário, disposto uniformemente ao longo do Oiapoque, pressupunha relações anteriores capazes de descrever unidades mais restritas, também iluminadas pela dádiva do caxiri. Entre os Waiãpi, essa bebida recebe um papel de articulação de instâncias festivas, das "pequenas" e mais frequientes às "grandes" que requerem uma montagem cuidadosa e a presença incisiva de grupos que se reconhecem como alheios (CALBALZAR, s/d). Pode-se mesmo dizer que o caxiri, mais que uma bebida exclusiva de momentos festivos, perfaz um contínuo que perpassa todos momentos coletivos da sociedade - das esferas inter-residenciais às intercomunitárias, e, até mesmo, interétnicas (sempre marcadas pelo excesso).

15 Viveiros de Castro (1986) afirma que entre os Araweté, grupo Tupi-Guarani do Pará meridional com o qual é possível traçar aqui um paralelo, a oposição entre convidados e anfitriões é expressa pela oposição entre o "dono do cauim", aquele cujo trabalho (produção do cauim) é análogo à produção de seres humanos, e o cantador, cuja posição no ritual é análoga à posição do inimigo-cativo Tupinambá (aquele que, ao cantar, anuncia sua execução). Trata-se da contraposição entre uma "função-mulher" - o dono do cauim como reprodutor - e uma "função-inimigo" - cantador como predador.

16 Antonella Tassinari (1998), referindo-se às comunidades Karipuna do rio Curipi atribui importância crucial para as festas grandes no interior do caldo interétnico que conforma a região do rio Uaçá, afluente do Oiapoque. Segundo a autora, nessas instâncias, potencializa-se o processo de elaboração de uma tradição comum, da definição de uma identidade coletiva, sustentada pela ênfase em um passado comum e pela replicação de círculos de reciprocidade (fundamentados na partilha do caxiri, elemento mínimo de qualquer empreendimento para estabelecer relações recíprocas). Trata-se de momentos em que os laços de parentesco se efetivam, reforçando a comunicação com os seres sobrenaturais.

\section{REFERÊNCIAS BIBLIOGRÁFICAS}

BOURDIEU, Pierre. 1980. Le sense pratique. Paris: Editions Minuit

CALBAZAR, Flora Dias. 1997. Trocas matrimoniais e relações de qualidade entre os Waiãpi do Amapá. Dissertação de Mestrado. São Paulo, Universidade de São Paulo.

s/d. Relatório de pesquisa, mimeo. 
CARNEIRO DA CUNHA, Manuela. 1996. "O futuro da questão indígena". In: GRUPPIONI, Luiz Donisete \& LOPES DA SILVA, Aracy. A temática indígena na sala de aula. São Paulo: MEC-FAPESP.

1998. "Pontos de vista sobre a floresta amazônica: xamanismo e tradução" In: Mana, Rio de Janeiro, Contracapa, $4 / 1$.

DUMONT, Louis. 1996. Homo Hierarchicus. São Paulo: Edusp.

ELIAS, Norbert. 1996. O Processo Civilizador. Vol. I. Uma história dos costumes. São Paulo: Zahar.

FARAGE, Nádia. 1991. As muralhas dos sertões. Os povos indígenas no Rio Branco e a colonização. Rio de Janeiro: Paz e Terra/ANPOCS.

FAUSTO, Carlos. 1997. A dialética da predação e familiarização entre os Parakanã da Amazônia Oriental: por uma teoria da guerra ameríndia. Tese de doutorado. Rio de Janeiro, Museu Nacional.

GALLOIS, Dominique. 1986. Migração, guerra e comércio: os Waiãpi. São Paulo: FFLCH-USP. Série Antropologia.

1988. O movimento na cosmologia waiãpi: criação, expansão e transformação do universo. Tese de Doutorado. São Paulo, FFLCH-USP.

1991. Relatório de Visita dos waiãpi do Amapari às aldeias do médio Oiapoque (Camopi, julho). Mimeo.

GALLOIS, Dominique \& CARELLI, Vincent. 1995. “Dois encontros mediados pelo vídeo”. In: Revista de Antropologia, São Paulo, Universidade de São Paulo, 38/1.

GALLOIS, Dominique \& KAHN, Marina. 1991. Livro de mapas, mimeo.

GRENAND, Pierre. 1982. Ansi parlaient nos ancêtres: essai d'ethnohistoire waiãpi. Paris, ORSTOM, Tr. 148.

GRENAND, Pierre \& Françoise. 1988. Les reserves foncieres en Guyane Française. Paris, mimeo. 1990. Les amérindiens et la France: conflit ou harmonie. Paris, mimeo.

1991. "L'impossible alliance. L'homme blanc selon les wayãpi centraux”, Paris, ORSTOM, mimeo.

HARRISON, Simon. 1991. "Ritual as intellectual property”. In: Man, Londres, Royal Anthropological Institute, 27/2.

LEPRETRE, Ludovic. 1991. Le projet de parc national en Guyane: nature patrioniale des environnementalistes versus appropriation territoriale des amérindiens Wayana. Mimeo, Paris, ORSTOM.

LÉVI-STRAUSS, Claude. 1971. "Finale” In: L'homme nu. Paris: Plon.

1976. “As organizações dualistas existem?” In: Antropologia estrutural. Rio de Janeiro: Biblioteca Tempo Universitário.

1982. As estruturas elementares do parentesco. São Paulo: Vozes.

LIMA, Tânia S. 1995. A parte do cauim. Etnografia Juruna. Tese de doutorado. Rio de Janeiro, Museu Nacional.

OVERING, Joanna. 1975. The Piaroa. A people from Orinoco Basin. Cambridge: Cambridge University Press.

1983. "Elementary Structures of Reciprocity: a comparative note on guianese, central brazilian and north-west amazon social-political thought" In: Antropologica, vol 59/62.

RIVIÈRE, Peter. 1984. Individual and Society in Guiana. Cambridge: Cambridge University Press.

SAHLINS, Marshall. 1997. “O pessimismo sentimental. Por que a cultura não é um objeto em extinção 
- Parte 1 e 2" In: Mana, Rio de Janeiro, Contra Capa, 3/1 e 3/2.

TASSINARI, Antonella Ma. Imperatriz. Contribuição à história e à etnografia do baixo Oiapoque: a composição das famílias Karipuna e a estruturação das redes de troca. Tese de Doutorado. São Paulo, USP.

VIVEIROS DE CASTRO, Eduardo. 1986. Araweté: os deuses canibais. Rio de Janeiro, Jorge Zahar Editor/ANPOCS.

1991. “O mármore e a murta". In: Revista de Antropologia, São Paulo, Universidade de São Paulo, 35.

1993. "Alguns aspectos do dravidianato amazônico" In: VIVEIROS DE CASTRO, Eduardo \& CARNEIRO DA CUNHA, Manuela. Amazônia - etnologia e história São Paulo: FAPESP.

1996. "Pronomes cosmológicos e o perspectivismo ameríndio" In: Mana, Rio de Janeiro, Contracapa, $2 / 2$.

\begin{abstract}
Based on the ethnography of the encounter between Waiãpi from Amapari, Brazil, and Waiãpi from Oiapoque, French Guiana, this article introduces a discussion about intercommunitary comunication in Guiana. Its focus is above all on ritual moments, recognized as champs of exchange and struggle of different points of view and discourses on the fact of living in such a situation which one may refer as "interethnic".
\end{abstract}

Uniterms: Intercommunitary comunication, interethnic situation, ritual.

Aceito para publicação em 22 de setembro de 1999. 